\title{
Material Split, Cut or Torn
}

National Cancer Institute

\section{Source}

National Cancer Institute. Material Split, Cut or Torn. NCI Thesaurus. Code C133509.

Problem associated with materials comprising the device are split, cut or torn due to external forces (e.g. wrenching or laceration) or internal forces (e.g. exceeding the tensile stress limits belonging to the materials used in the device construction). 